\title{
Treatment of polymyalgia rheumatica with intramuscular injections of depot methylprednisolone
}

\author{
Bhaskar Dasgupta, Jeremy Gray, Luke Fernandes, Cedric Olliff
}

\begin{abstract}
Although the treatment of patients with polymyalgia rheumatica by corticosteroids given by mouth is effective, it is often accompanied by multiple side effects. Various studies have shown that the steroid related complications are proportional to the cumulative dose of steroids administered. In a prospective study of 16 patients with polymyalgia rheumatica the effects of regular intramuscular injections of methylprednisolone over 12 months were evaluated. Remission of disease was achieved with injections of $120 \mathrm{mg}$ of methylprednisolone every three weeks for 12 weeks. Subsequent disease remission was maintained by monthly injections of methylprednisolone on a reducing schedule of dose. The treatment was efficacious, safe, well tolerated over one year, and showed no suppression of the hypothalamic pituitary adrenal axis at 12 weeks after initiation of treatment. Such a mode of steroid treatment results in a considerably lower cumulative steroid dose than with conventional doses of prednisolone given by mouth. These results will be further evaluated in a controlled trial using intramuscular injections of methylprednisolone and prednisolone given by mouth for the treatment of polymyalgia rheumatica.
\end{abstract}

Department of Rheumatology, Royal Sussex

County Hospital,

Brighton,

Sussex,

UK

J Gray

B Dasgupta

L Fernandes

Department of

Pharmacy,

Brighton Polytechnic,

Brighton,

Sussex,

UK

C Olliff

Correspondence to:

Dr B Dasgupta,

Southend General Hospital,

Prittlewell Chase,

West Cliff on Sea, Essex,

UK.

Accepted for publication

30 November 1990
Corticosteroids are the most important form of treatment for patients with polymyalgia rheumatica. This is illustrated by the fact that the response to systemic steroids is an integral feature of the disease description. ${ }^{1}$ Although remission can be achieved fairly easily with low doses of steroids (conventionally $10-20 \mathrm{mg}$ prednisolone daily), the treatment can last for several years. This often results in multiple side effects, of which steroid induced osteoporosis is probably the most significant. ${ }^{2}$ Previous studies have clearly related the incidence of side effects of steroids in polymyalgia rheumatica to the cumulative dose of steroids administered. ${ }^{2-4}$ Lowering the dose of prednisolone given by mouth, however, results in a higher incidence of disease relapse. ${ }^{5} \mathrm{~A}$ method of steroid treatment that combines a low cumulative dosage with good efficacy would therefore be a potential improvement in the treatment of polymyalgia rheumatica.

Methylprednisolone is a synthetic analogue of prednisolone. ${ }^{6}$ It combines a $20 \%$ higher glucocorticoid activity with lower mineralocorticoid action. Methylprednisolone acetate, which can be injected, is often used for intra-articular and soft tissue injections in several rheumatic conditions. At the rheumatology unit, Guy's Hospital, London, the depot preparation of methylprednisolone acetate (Depo-Medrone, Upjohn) has been injected intramuscularly during the induction of chrysotherapy for the treatment of rheumatoid arthritis. ${ }^{7}$

In an open study we treated 16 newly diagnosed patients with polymyalgia rheumatica with regular intramuscular injections of methylprednisolone (Depo-Medrone). The preliminary results suggest that this treatment is effective, safe, and well tolerated.

\section{Patients and methods}

Sixteen newly diagnosed patients with polymyalgia rheumatica, fulfilling the criteria of Jones and Hazleman, ${ }^{8}$ were entered into the study. Patients with clinical features of giant cell arteritis were excluded. Also excluded were patients who had previously received steroids for polymyalgia rheumatica by mouth and patients with any contraindications to steroid treatment. Patients were given intramuscular injections of $120 \mathrm{mg}$ of methylprednisolone every three weeks for the first 12 weeks. The patients were subsequently treated with intramuscular injections of methylprednisolone every month with the dose reduced by $20 \mathrm{mg}$ every three months. The patients were returned to their previously higher dose if their symptoms increased again after the reduction in dose. The severity of disease was assessed clinically using morning stiffness and visual analogue scales for pain. The laboratory parameters measured included a full blood count, erythrocyte sedimentation rate, and the determination of immunoglobulins. Lymphocyte subsets of peripheral blood were measured at onset in nine patients by standard techniques. ${ }^{9}$ The hypothalamic pituitary adrenal axis was assessed three months after the start of treatment by measuring the diurnal cortisol rhythm and by the metyrapone test. ${ }^{9 a}$ Concentrations of methylprednisolone in serum samples after the intramuscular injection of $120 \mathrm{mg}$ were determined in five patients by high performance liquid chromatography ${ }^{10}$ after pretreatment with Chem-Elut. The detection limit was $2 \mathrm{ng} / \mathrm{ml}$ and the standard deviation of the assay was $8 \cdot 3 \%$.

\section{STATISTICAL ANALYSIS}

The changes in morning stiffness and visual analogue scale were analysed using Wilcoxon's signed rank tests and the changes in haemoglobin and erythrocyte sedimentation rate were analysed using the paired Student's $t$ test. 


\section{Results}

All the patients in our study had complete relief of symptoms within 48 hours of the first intramuscular injection of methylprednisolone. Table 1 shows that there were highly significant decreases in morning stiffness and visual analogue scale and a significant and sustained increase in haemoglobin with treatment. The erythrocyte sedimentation rate also showed a significant and sustained decrease; figure 1 shows the gradual decrease in erythrocyte sedimentation rate over the first 12 weeks. The immunoglobulin concentrations were normal at onset apart from two patients-these returned to normal with treatment. The diurnal cortisol rhythm (at 0900 and midnight) was preserved in all patients after 12 weeks of treatment. There were normal increases of 11-deoxycortisol concentrations after the metyrapone test-this suggests normal function of the hypothalamic pituitary adrenal axis in the seven patients in whom this test was performed. Immunofluorescence analysis showed a marked decrease in the concentrations of the CD8 (supressor/cytotoxic) subset in the peripheral blood of eight of nine patients

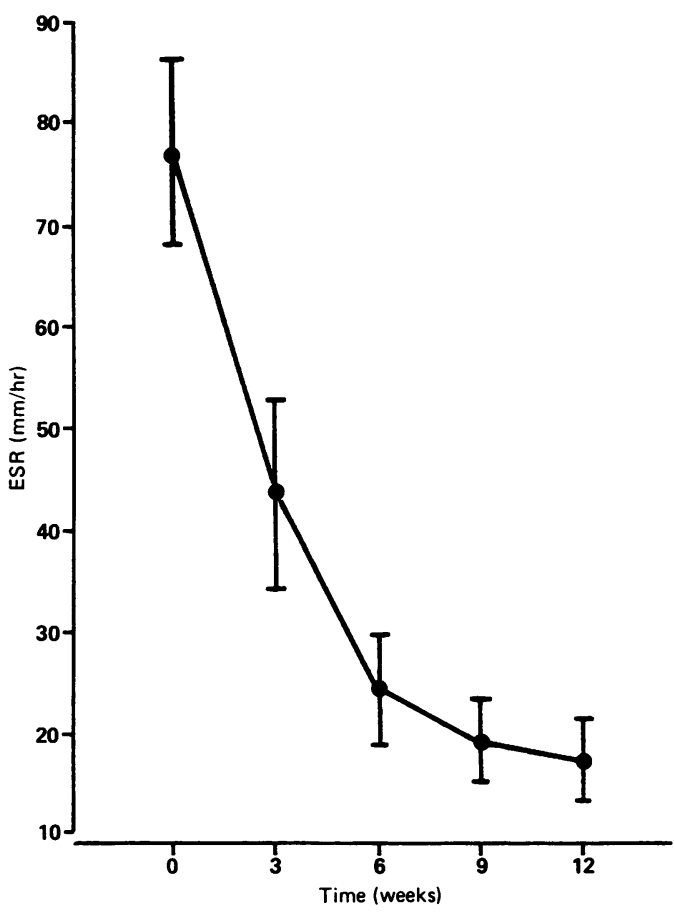

Figure 1 Changes in the erythrocyte sedimentation rate over the first 12 weeks of treatment for 16 patients with polymyalgia rheumatica treated by the intramuscular injection of methylprednisolone.

Table 1 Clinical and laboratory parameters (expressed as mean (SEM)) monitored over 12 months in patients with polymyalgia rheumatica treated with intramuscular methylprednisolone. Changes in all the parameters are highly significant

\begin{tabular}{|c|c|c|c|c|}
\hline \multirow{2}{*}{$\begin{array}{l}\text { Clinical and } \\
\text { laboratory } \\
\text { parameter }\end{array}$} & \multicolumn{4}{|c|}{ Duration of treatment (months) } \\
\hline & 0 & 3 & 6 & 12 \\
\hline \multirow[t]{2}{*}{$\begin{array}{l}\text { Morning stiffness (min) } \\
\text { Visual analogue scale (min) } \\
\text { Haemoglobin (g/l) } \\
\text { Erythrocyte sedimentation } \\
\text { rate }(\mathrm{mm} / \mathrm{h})\end{array}$} & $\begin{aligned} 192 & (24) \\
82 & (4 \cdot 7) \\
120 & (3)\end{aligned}$ & $\begin{array}{r}5 \cdot 6(2 \cdot 7) \\
16 \cdot 1(14)^{*} \\
137(3 \cdot 4) \dagger\end{array}$ & $\begin{array}{r}5 \cdot 5(4 \cdot 0)^{*} \\
9(1 \cdot 8)^{*} \\
136(3 \cdot 2) \dagger\end{array}$ & $\begin{array}{c}2 \cdot 0(2) \\
7(2 \cdot 0)^{*} \\
135(3) \dagger\end{array}$ \\
\hline & $77(9)$ & $19(4) \ddagger$ & $22(5) \ddagger$ & $19(3) \ddagger$ \\
\hline
\end{tabular}

${ }^{*} \mathrm{p}<0.001$.

$\neq \mathrm{t}<0.01$.

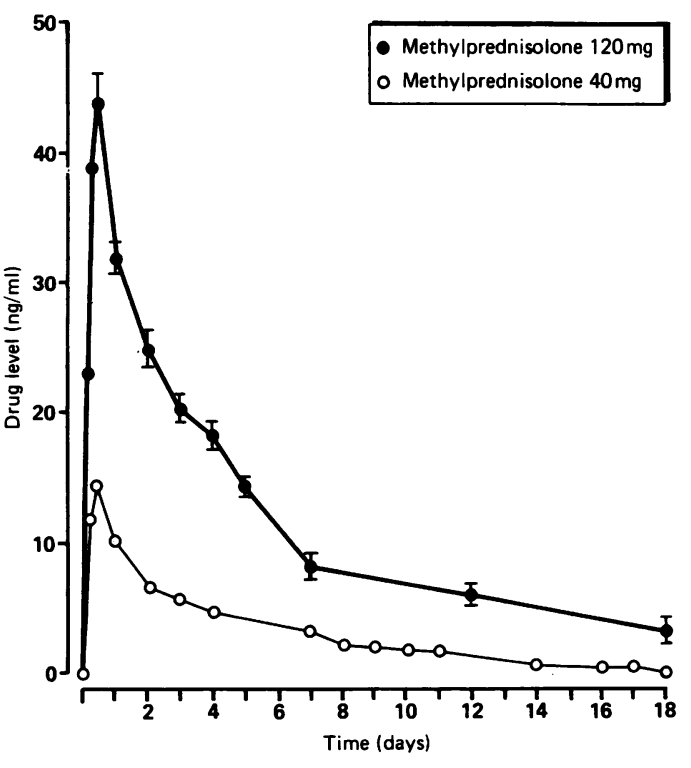

Figure 2 Release profile of $120 \mathrm{mg}$ of methylprednisolone injected intramuscularly compared with the manufacturer's (Upjohn) data on the release profile of $40 \mathrm{mg}$ of the same drug.

tested at onset (mean $14.0 \%$; normal range $28-46 \%$ ).

During the course of the study three patients were returned to conventional doses of prednisolone given by mouth. One patient, despite a dramatic early response to methylprednisolone, was unwilling to receive methylprednisolone at months four and five of treatment. This resulted in a rebound flare of polymyalgia rheumatica, which failed to respond to subsequent methylprednisolone treatment, but did respond to high doses of steroid given by mouth. Another patient was elderly (aged 85 years) and unable to attend regularly for injections after a fall and a complicated fracture of the neck of the femur. The third patient showed a dramatic early response at three months after the start of treatment (increase in haemoglobin from 89 to $133 \mathrm{~g} / \mathrm{l}$, decrease in erythrocyte sedimentation rate from 119 to $29 \mathrm{~mm} / \mathrm{h}$ ), but experienced an increase in disease severity after five months of treatment. Three patients showed minor bruising after 12 months of treatment. No other side effects were noted.

Figure 2 shows the release profile for the intramuscular injection of $120 \mathrm{mg}$ of methylprednisolone in five patients determined by high performance liquid chromatography. There was a concentration peak at $6-8$ hours of $43.5 \mathrm{ng} / \mathrm{ml}$, with a subsequent sharp downwards slope. At day seven the mean concentration in serum samples was $8 \mathrm{ng} / \mathrm{ml}$; methylprednisolone was barely detectable in serum samples at day $18(2 \mathrm{ng} / \mathrm{ml}$.)

\section{Discussion}

A regimen of intramuscular injection of $120 \mathrm{mg}$ of methylprednisolone every three weeks gave a satisfactory induction of remission in 16 patients with untreated polymyalgia rheumatica. This remission of disease was subsequently maintained in most patients by monthly injections of methylprednisolone at decreasing doses. At the 
end of one year all patients in the study were receiving a monthly injection of $40-60 \mathrm{mg}$ of methylprednisolone. This treatment was acceptable, well tolerated, and showed no local or systemic side effects apart from minor bruising in three patients. The patients received injections at the outpatient clinic, although it is feasible for patients to receive intramuscular injections of methylprednisolone regularly at a general practitioner's surgery; this treatment also ensures compliance.

Over the first 12 weeks the cumulative dose of methylprednisolone administered was $480 \mathrm{mg}$ (equivalent to $600 \mathrm{mg}$ of prednisolone). In contrast, if an average daily dose of $10 \mathrm{mg}$ of prednisolone is assumed in the conventional treatment of polymyalgia rheumatica (it is often higher), then the cumulative dose at 12 weeks would be $840 \mathrm{mg}$ - that is, $40 \%$ greater than that for the intramuscular injection of methylprednisolone. This difference between the cumulative dose of prednisolone given by mouth and the intramuscular injection of methylprednisolone is further accentuated during maintenance treatment. For example, at 12 months all our patients were receiving $40-60 \mathrm{mg}$ of methylprednisolone each month-that is $1 \cdot 7-2 \cdot 5 \mathrm{mg}$ of prednisolone daily.

Various studies have reported different incidences of steroid side effects in the treatment of polymyalgia rheumatica. Most, including a recent study by Kyle and Hazleman, ${ }^{2}$ have shown that steroid side effects occur in proportion to the total steroid dose administered. ${ }^{2-4}$ Our study suggests that with the intramuscular injection of methylprednisolone it is possible to maintain disease remission with a relatively small total intake of steroids. Whether this form of treatment results in fewer long term side effects needs to be established by a controlled trial.

It is encouraging that this regimen of steroid treatment preserves the normal response of the hypothalamic pituitary adrenal axis after 12 weeks of treatment. This may be related to the release profile of methylprednisolone injected intramuscularly. As shown in our study of the release of $120 \mathrm{mg}$ of methylprednisolone and in the manufacturer's data for the release of $\mathbf{4 0 ~} \mathrm{mg}$ of methylprednisolone injected intramuscularly (figure 2), there is an early peak between six and eight hours followed by a relatively rapid decline over the first week. Thereafter there is a much slower decrease in weeks two and three. This gradually decreasing concentration of the drug probably accounts for the sustained therapeutic effect while allowing the full recovery of the hypothalamic pituitary adrenal axis before the next injection. Although the hypothalamic pituitary adrenal axis has not been investigated during steroid treatment by mouth in polymyalgia rheumatica, there is evidence that such treatment in other rheumatic and non-rheumatic diseases does cause hypothalamic pituitary adrenal axis suppression. ${ }^{11}$ Thus the lack of hypothalamic pituitary adrenal axis suppression may constitute an additional important advantage of the intramuscular injection of methylprednisolone over prednisolone given by mouth. This avoidance of dependence on steroids may make the intramuscular injection of methylprednisolone, as used in our treatment regimen, an attractive alternative in many clinical situtations where conventionally low doses of prednisolone given by mouth are used.

It is interesting that although the concentrations of methylprednisolone in serum samples decrease to $8 \mathrm{ng} / \mathrm{ml}$ by day seven, adequate control of the disease is maintained for the next two to three weeks after a single intramuscular injection of $120 \mathrm{mg}$ of methylprednisolone. Only at 48-72 hours before the next injection was a slight increase in muscle stiffness and pain found. Four such intramuscular injections of methylprednisolone were sufficient to cause a smooth reduction of erythrocyte sedimentation rate to normal values within the first 12 weeks (fig 1). Corkill $e t a l^{7}$, using a similar regimen in active rheumatoid arthritis, found that although there was a relative decrease in erythrocyte sedimentation rate in the group treated with steroids, the mean erythrocyte sedimentation rate never reached normal values. This dissimilar response to steroids in polymyalgia rheumatica and rheumatoid arthritis (often a differential diagnosis with its polymyalgic onset in the elderly) highlights the high sensitivity to steroids of the former disease.

The cause of this dissimilar response remains unexplained. Glucocorticoids act by binding to specific, cytosolic glucocorticoid receptors and there is in vitro and in vivo evidence that the cellular sensitivity to glucocorticoids may correlate with the activity and concentration of intracellular glucocorticoid receptors. ${ }^{13} 14$ Such a variation may be responsible for the difference in sensitivity to steroids in polymyalgia rheumatica and rheumatoid arthritis.

The low numbers of peripheral blood CD8 + lymphocytes in most of our patients are consistent with previous reports of such an immunoregulatory abnormality in polymyalgia rheumatica and giant cell arteritis. ${ }^{9} 15$ A study by Elling et $a l^{16}$ determined the positive predictive value of a significantly low number of $\mathrm{CD} 8+\mathrm{T}$ cells in polymyalgia rheumatica or giant cell arthritis to be $85 \%$ in 108 patients who had a temporal artery biopsy.

Having established that this regimen of the intramuscular injection of methylprednisolone is a safe, well tolerated, and yet an efficacious treatment for polymyalgia rheumatica, we now intend to evaluate the efficacy and metabolic side effects of this regimen compared with conventional doses of prednisolone given by mouth. We plan to carry out a prosective, controlled, randomised, and initially double blind study comparing the intramuscular injection of methylprednisolone with prednisolone given by mouth over two years for the treatment of polymyalgia rheumatica. An important aspect of the study will be to monitor carefully the extent of steroid induced osteoporosis by measuring the mineral density of bone in the two groups.

Although most studies identify osteopenia as the principal complication of long term steroid treatment, the true incidence of osteoporosis in such patients is unknown as there are few studies which report prospective data on bone 
density measurements. ${ }^{17}$ The rate of steroid induced bone loss also remains to be determined, although one study suggests that there is rapid early loss and a plateau after about six months. ${ }^{18}$ The question of whether different routes of steroid administration may result in different metabolic effects has not been studied before and a controlled study of methylprednisolone versus prednisolone given by mouth for two years will, it is hoped, go some way towards answering these questions. Such a study will also allow a longitudinal study of immunoregulatory abnormalities such as CD8 lymphopenia in patients with polymyalgia rheumatica.

1 Hazleman B L. Polymyalgia rheumatica and giant cell arteritis. In: Scott J T, ed. Copeman's textbook of the rheumatic diseases. 6th ed. Edinburgh: Churchill Livingstone, 1986: 1278-91.

2 Kyle V, Hazleman B L. Treatment of polymyalgia rheumatica and giant cell arteritis II. Relation between steroid dose and steroid side effects. Ann Rheum Dis 1989; 48: 662-6.

3 Delecoeuillerie D, Joly P, Cohen de Lara A, Paolaggi, J B. Polymyalgia rheumatica and temporal arteritis: a retrospective analysis of prognostic features and different corticosteroid regimens (11 year survey of 210 patients). Ann Rheum Dis 1988;9: 733-9.

4 de Deuxchaisnes $\mathrm{C}$ N, Devogelaer J P, Esselinck W, et al. The effect of low dosage glucocorticoids on bone mass in rheumatoid arthritis: a cross-sectional and a longitudinal study using single photon absorptiometry. Adv Exp Med Biol 1984; 171: 210-39.

5 Kyle V, Hazleman B L. Treatment of polymyalgia rheumatica and giant cell arteritis $I$. Steroid regimens in the first two months. Ann Rheum Dis 1989; 48: 658-61.

6 Haynes R C, Murad F. Adrenocorticotrophic hormone, adrenocortico steroids and their synthetic analogues; inhibitors of adrenocortical steroids. In: Goodman A,
Gilman L S, Goodman T W, Rall T W, Murad F, eds. The pharmacological basis of therapeutics. 7th ed. New York Macmillan, 1985: 1459-89.

7 Corkill M M, Kirkham B W, Chikanza I C, Gibson T, Panayi G S. Intramuscular depot methylprednisolone induction of cinrysotherapy in rheumatoid arthritis: a 24-week randomized controlled trial. Br.7 Rheumatol, 1990; 29: 274-9.

8 Jones J G, Hazleman B L. The prognosis and management of polymyalgia rheumatica. Ann Rheum Dis 1981; 40: 1-5.

9 Dasgupta B, Duke O, Timms A M, Pitzalis C, Panayi G S. Selective depletion and activation of CD8 + lymphocytes from peripheral blood of patients with polymyalgia rheumatica and giant cell arteritis. Ann Rheum Dis 1989; 48: 307-11.

9a Liddle G W. The adrenals. In: Williams $\mathbf{R} \mathbf{H}$, ed. Textbook of endocrinology. 6th ed. Philadelphia: Saunders, 1981:

10 Passey R B, Blick K E. Serum and urine methylprednisolone and methylprednisolone sodum succinate assay by a highly and methylprednisolone sodum succinate assay by a hit

11 Byron M A, Jackson J, Ansell B M. Effect of different corticosteroid regimens on hypothalamic-pituitary-adrenal axis and growth

12 Rodger R S C, Watson M J, Sellars L, Wilkinson R, Ward M K, Kerr D N S. Hypothalamic-pituitary-adrenocortical suppression and recovery in renal transplant patients returning to maintenance dialysis. $Q \mathcal{F}$ Med 1986; 61: $1039-46$.

13 Scheidereit C, Krauter P, von der Ahe, et al. Mechanism of gene regulation by steroid hormone. F Steroid Biochem 1986; 24: 19-24.

14 Gustafsson J A, Carlstedt-Duke J, Poellinger L, et al. Biochemistry, molecular biology and physiology of the glucocorticoid receptor. Endocr Rev 1987; 8: 185-234.

15 Benlarache C, Segond P, Angiuer L, Bouret J P. Decrease of OKT8 positive $\mathrm{T}$ cell subset in polymyalgia rheumatica. OKT8 positive $T$ cell subset in

16 Elling P, Olsson A, Elling H. CD8 + T lymphocyte subset in giant cell arteritis and related disorders. $\mathcal{F}$ Rheumatol 1990 17: $225-7$

17 Lukert B P, Raisz L G. Glucocorticoid induced osteoporosis: pathogenesis and management. Ann Intern Med 1990; 112 352-64.

18 Gennari C. Glucocorticoids and bone. In: Peck W A, ed. Bone and mineral research. Vol 3. Amsterdam: Elsevier, 1985: 213-32. 